\title{
RECIPROCAL REINSURANCE TREATIES
}

\author{
BY KARL BORCH
}

\section{Introduction}

1.1. In this paper we shall study the situation of two insurance companies which are negotiating with the view of concluding a reciprocal reinsurance treaty. We assume that the two companies are under no compulsion to reach an agreement. This means that if the companies conclude a treaty, the treaty must be such that both companies consider themselves better off than without any treaty. We futher assume that no third company can break into the negotiations. This means that the two companies either have to come to terms, or be without any reinsurance.

1.2. How the two parties reach an agreement in a situation like this, is one of the classical problems of theoretical economics. It is usually referred to as the "Bargaining Problem". The problem appears very simple, but this is a deception. It has proved extremely difficult to formulate generally acceptable assumptions which give the problem a determinate solution. The "Theory of Games", developed by von Neumann and Morgenstern (I0), does not give a determinate solution, but it has greatly increased our understanding of such problems, and the present paper will draw heavily on that theory.

1.3. The situation which we propose to study, is very simple, may be too simple to have any bearing on reinsurance negotiations in real life. If there exists a reinsurance market, which also is a perfect market in the sense given to this term in economic theory, bartering between two companies does not make any sense. They could both do equally well or better by dealing in the market at the market price.

To illustrate the point, let us consider two suburban housewives who go down-town for shopping. If they both do their shopping according to a well prepared list at a perfect super market, neither of them will gain anything by swopping the goods they have bought, 
after they get home to their suburb. However, if the two housewives go bargain-hunting at a sale, they may both gain considerably by a friendly private barter after their return to peaceful suburban surroundings.

It seems likely that the reinsurance market is more similar to the bargain counter than to the well-ordered super market, where everything is available at a fixed price. If this is so, there will be scope for reciprocal treaties, also between companies which have made full use of their possibilities of dealing in the market.

1.4. Even if the model we propose to study is too simple to have any practical value, it may still be of interest to analyse it in some detail. Only if we gain a full understanding of the simplest possible case, that of the two companies, can we hope to tackle the more complicated cases with some success.

\section{The Model}

2.1. We assume that Company I has a portfolio of insurance contracts such that $F_{1}\left(x_{1}\right)$ is the probability that the total amount of claims made under these contracts shall not exceed $x_{1}$. We shall call $F_{1}\left(x_{1}\right)$ the risk distribution of Company I. We assume further that the company holds funds amounting to $S_{1}$ which are available to pay claims. The two elements $F_{1}\left(x_{1}\right)$ and $S_{1}$ determine what we shall call the risk situation of the company.

The company will be solvent in the ordinary actuarial sense if

$$
\int_{0}^{\infty} x_{1} d F_{1}\left(x_{1}\right) \leq S_{1}
$$

Similary we assume that Company II has a risk distribution $F_{2}\left(x_{2}\right)$ and funds $S_{2}$. We assume that the random variables $x_{1}$ and $x_{2}$ are statistically independent.

2.2. The companies have no control over the random variables $x_{1}$ and $x_{2}$. If claims amounting to $x_{1}$ and $x_{2}$ occur, the companies have to meet these claims. Unless they agree otherwise, Company I will pay the amount $x_{1}$ and Company II $x_{2}$. However, the companies are completely free to agree on any other way of dividing the total amount of claims $x_{1}+x_{2}$ between themselves. The companies can for instance agree that Company I shall pay an amount $y\left(x_{1}, x_{2}\right)$ if claims amounting to $x_{1}$ and $x_{2}$ occur in the two portfolios. Company 
II will then have to pay the remainder, i.e. $x_{1}+x_{2}-y\left(x_{1}, x_{2}\right)$.

Hence any real-valued function $y\left(x_{1}, x_{2}\right)$ defined for all positive values of $x_{1}$ and $x_{2}$ will represent a possible agreement between the two companies, i.e. a reciprocal reinsurance treaty.

2.3. The function $y\left(x_{1}, x_{2}\right)$ depends only on the total amounts of claims $x_{1}$ and $x_{2}$. Hence a function of this kind can only represent a treaty which is truly collective in the sense that the reinsurer's liability depends only on the total amount of claims. Whether this amount has arisen as a result of one big claim or a large number of small ones, is irrelevant. Many, if not most, of the treaties we meet in practice are not collective in this sense.

It would not be difficult to generalise our model so that such non-collective treaties can be included. However, this would necessitate considering separately each contract in the portfolio and would certainly lead to very cumbersome formulae. It seems preferable at the present stage to avoid such arithmetical complications and confine our study to collective treaties.

2.4. It may be desirable to give a few examples which will illustrate the kind of treaties which can be represented by a function $y\left(x_{1}, x_{2}\right)$.

(i) No Treaty. If the companies do not conclude any agreement, it is obvious that

$$
y\left(x_{1}, x_{2}\right)=x_{1}
$$

(ii) Stop Loss Cover. It is agreed that if claims against Company I exceed $N$, the excess shall be paid by Company II. This treaty gives:

$$
\begin{aligned}
& y\left(x_{1}, x_{2}\right)=x_{1}+P \text { for } x_{1} \leq N \\
& =N+P \text { for } N<x_{1}
\end{aligned}
$$

where $P$ is the premium Company I pays for the cover.

If we want to take into consideration the possibility that Company II may be unable to meet its commitments, we get a more complicated function. If other claims against Company II have priority over claims under the treaty, we obtain:

$$
\begin{aligned}
y\left(x_{1}, x_{2}\right)= & x_{1}+P \text { for } x_{1} \leq N \text { for all } x_{2} \\
= & N+P \text { for } N<x_{1} \text { and } x_{2}<S_{2}+P+N-x_{1} \\
= & x_{1}+x_{2}-S_{2} \text { for } N<x_{1} \text { and } S_{2}+P+N-x_{1} \\
& \quad<x_{2}<S_{2}+P \\
= & x_{1}+P \text { for } N<x_{1} \text { and } S_{2}+P<x_{2}
\end{aligned}
$$


In practice it is not usual to consider the possibility that the reinsurer shall become insolvent, but in our artificial two-company world such considerations may be important. Nevertheless, we will ignore them in the following.

(iii) Quota Share Treaty. Company I agrees to cede a quota $k$ of each risk in its portfolio, against a commission $\alpha$. This is expressed by:

$$
y\left(x_{1}, x_{2}\right)=(I-k) x_{1}+k P_{1}-\alpha k P_{1}
$$

where $P_{1}$ is the premium of the total portfolio of Company $\mathrm{I}$.

(iv) Quota Share with sliding scale commission.

Let the commission be:

$$
\begin{aligned}
& \alpha_{1} \text { for } \frac{x_{1}}{P_{1}}<r_{1} \\
& \alpha_{2} \text { for } \frac{x_{1}}{P_{1}}>r_{2} \\
& \frac{\alpha_{1}\left(r_{2}-\frac{x_{1}}{P_{1}}\right)+\alpha_{2}\left(\frac{x_{1}}{P_{1}}-r_{1}\right)}{r_{2}-r_{1}} \text { for } r_{1} \leq \frac{x_{1}}{P_{1}} \leq r_{2}
\end{aligned}
$$

Inserting this in the expression in the previous example, we find:

$$
\begin{aligned}
& y\left(x_{1}, x_{2}\right)=(\mathrm{I}-k) x_{1}+\left(\mathrm{I}-\alpha_{1}\right) k P_{1} \text { for } \frac{x_{1}}{P_{1}}<r_{1} \\
& =(\mathrm{I}-k) x_{1}+\left(\mathrm{I}-\alpha_{2}\right) k P_{1} \text { for } \frac{x_{1}}{P_{1}}>r_{2}
\end{aligned}
$$

For $r_{1} \leq \frac{x_{1}}{P_{1}} \leq r_{2}$ we have:

$$
\begin{aligned}
y\left(x_{1}, x_{2}\right) & =(\mathrm{r}-k) x_{1}+\left(\mathrm{I}-\frac{\alpha_{1}\left(r_{2}-\frac{x_{1}}{P_{1}}\right)+\alpha_{2}\left(\frac{x_{1}}{P_{1}}-r_{1}\right)}{r_{2}-r_{1}}\right) k P_{1} \\
& =\left(\mathrm{I}-k+k \frac{\alpha_{1}-\alpha_{2}}{r_{2}-r_{1}}\right) x_{1}+k P_{1}-\frac{r_{2} \alpha_{1}-r_{1} \alpha_{2}}{r_{2}-r_{1}} k P_{1}
\end{aligned}
$$

In practice we frequently find treaties where $\alpha_{1}+r_{1}=\alpha_{2}+r_{2}$. Golding (8) gives an example where $r_{1}=0,46, r_{2}=0,65$, and $\alpha_{1}+r_{1}=\alpha_{2}+r_{2}$ is approximately 0,975 . In this case we will have 


$$
y\left(x_{1}, x_{2}\right)=x_{1}+0,025 k P_{1} \text { for } 0,46<\frac{x_{1}}{P_{1}}<0,65
$$

Benktander (2) has with some justification called a treaty of this kind an "Imperfect Nonsense Treaty", perfection being achieved as $r_{1} \rightarrow 0$ and $r_{2} \rightarrow \infty$.

2.5. We now assume that the two companies open negotiations with the purpose of improving their risk situations. The outcome of these negotiations will be a reciprocal treaty, which we assume can be represented by a function $y\left(x_{1}, x_{2}\right)$. However, the purpose stated has no meaning, unless the companies have some scale of value which will enable them to decide whether one risk situation is better than another.

It seems almost self-evident that an insurance company must have such a scale of value in order to be able to decide in a rational manner whether it shall accept or reject any contract which is offered. If we assume that this scale is complete, in the sense that it can be applied in any situation, without ever leading to inconsistencies and discontinuities, this will have far reaching implications. The precise formulation of these assumptions and their consequences have been discussed in some detail in a previous paper (5) and will not be repeated here.

2.6. If an insurance company states that $S$ is the lowest price at which it will accept responsibility for a portfolio with risk distribution $F(x)$, the company must somehow consider that the advantage of receiving the amount $S$ with certainty just balances the disadvantage of assuming liability for the claims which may occur in the portfolio. This equivalence between a payment made with certainty and a payment which is a random variable, is the basis for all insurance contracts.

Assume now that $u(x)$ is the value or utility the company attaches to the prospect of receiving an amount $x$ with certainty. From the assumptions mentioned in the preceeding paragraph it then follows that the company will attach a utility $U(S, F(x))$ to a risk situation with elements $S$ and $F(x)$, where

$$
U(S, F(x))=\int_{0}^{\infty} u(S-x) d F(x)
$$

This is the far reaching implication referred to. It should be 
noted that $u(x)$, and hence $U(S, F(x))$ are determined only up to a linear transformation. The function $u(x)$ is usually referred to as the utility of money to the company. This function should be interpreted as a rule for computing the certain payment which is equivalent to a risk situation. We will assume that $u(x)$ is a nondecreasing differentiable function of $x$.

2.7. The purpose of the negotiation between the companies can now be stated in a more precise manner. Let $u_{1}(x)$ be the utility of money to Company I. The Company's utility in the initial situation is then

$$
U_{1}(0)=\int_{0}^{\infty} u_{1}\left(S_{1}-x_{1}\right) d F_{1}\left(x_{1}\right)
$$

The reinsurance treaty defined by $y\left(x_{1}, x_{2}\right)$ will change the company's utility to:

$$
U_{1}(y)=\int_{0}^{\infty} \int_{0}^{\infty} u_{1}\left(S_{1}-y\left(x_{1}, x_{2}\right)\right) d F_{1}\left(x_{1}\right) d F_{2}\left(x_{2}\right)
$$

(It may be more consistent if we write $U_{1}\left(x_{1}\right)$ for the utility in the initial situation, but we shall prefer $\left.U_{1}(0)\right)$.

In the negotiations Company I will try to secure agreement on a function $y\left(x_{1}, x_{2}\right)$ which gives $U_{1}(y)$ the highest possible value. If $u_{2}(x)$ is the utility of money to Company II, this company has an initial utility of

$$
U_{2}(0)=\int_{0}^{\infty} u_{2}\left(S_{2}-x_{2}\right) d F_{2}\left(x_{2}\right)
$$

The treaty defined by $y\left(x_{1}, x_{2}\right)$ will change this utility to

$$
U_{2}(y)=\int_{0}^{\infty} \int_{0}^{\infty} u_{2}\left(S_{2}-x_{1}-x_{2}+y\left(x_{1}, x_{2}\right)\right) d F_{1}\left(x_{1}\right) d F_{2}\left(x_{2}\right)
$$

In the negotiations Company II will try to obtain the greatest possible value of $U_{2}(y)$. Since $u_{1}(x)$ and $u_{2}(x)$ are non-decreasing functions, it is clear that the two companies are pursuing objectives which are directly opposed and that they will have to reach a compromise. The outcome of the negotiations will be a function $y\left(x_{1}, x_{2}\right)$ which is optimal in the sense that both parties consider that it represents the best treaty they could obtain in the given situation. 


\section{The Optimal Treaty}

3.1. In order to determine the optimal treaty, we must make some assumptions as to the manner in which the negotiations are conducted. We assume that the companies act rationally and that they co-operate. This implies that they will not agree on a function $\bar{y}\left(x_{1}, x_{2}\right)$ if there exists another function $y\left(x_{1}, x_{2}\right)$ such that

$$
U_{1}(\bar{y}) \leq U_{1}(y) \text { and } U_{2}(\bar{y}) \leq U_{2}(y)
$$

where both equality signs cannot hold simultaneously.

$\bar{y}\left(x_{1}, x_{2}\right)$ is clearly inferior to $y\left(x_{1}, x_{2}\right)$, since the latter function gives a higher utility to at least one of the companies. We say that $\bar{y}\left(x_{1}, x_{2}\right)$ is dominated by $y\left(x_{1}, x_{2}\right)$. The set of functions $y\left(x_{1}, x_{2}\right)$ which are not dominated is referred to as the Pareto optimal set.

It follows from our assumptions of rationality that neither company will agree to a function $y\left(x_{1}, x_{2}\right)$ if it gives a lower utility than the company has in the initial situation. The company will be better off by refusing to conclude a treaty.

From our assumptions it follows that the optimal treaty is represented by a function $y\left(x_{1}, x_{2}\right)$ with the following properties:

(i) It belongs to the Pareto optimal set.

(ii) It satisfies the conditions:

$$
U_{1}(0) \leq U_{1}(y) \text { and } U_{2}(0) \leq U_{2}(y)
$$

3.2. These conditions will in general define a set of functions, and not a unique optimal function. To get a determinate solution to our problem we must make additional assumptions. This can be done in several ways. The most general and most attractive is probably the set of axioms proposed by Nash (9).

The basic assumptions made by Nash is that in a completely symmetric situation two rational bargainers will agree to maximise the joint gain, and then divide it equally between themselves. Applied to our particular case, this means that the two companies will agree upon the function $y\left(x_{1}, x_{2}\right)$ which maximises the product:

$$
\left\{U_{1}\left(y\left(x_{1}, x_{2}\right)\right)-U_{1}(0)\right\}\left\{U_{2}\left(y\left(x_{1}, x_{2}\right)\right)-U_{2}(0)\right\}
$$

This function will be referred to as the Nash solution to our problem.

3.3. We will now determine the Pareto optimal set. We assume that $y\left(x_{1}, x_{2}\right)$. belongs to this set, and we consider the function: 


$$
\bar{y}\left(x_{1}, x_{2}\right)=y\left(x_{1}, x_{2}\right)+\varepsilon\left(x_{1}, x_{2}\right)
$$

where $\varepsilon\left(x_{1}, x_{2}\right)$ is an arbitrary function of small absolute value.

The assumptions that $y\left(x_{1}, x_{2}\right)$ is Pareto optimal implies that the two inequalities

$$
\begin{aligned}
& \Delta U_{1}=U_{1}(\bar{y})-U_{1}(y)>0 \\
& \Delta U_{2}=U_{2}(\bar{y})-U_{2}(y)>0
\end{aligned}
$$

cannot hold simultaneously for any $\varepsilon\left(x_{1}, x_{0}\right)$.

We have for Company I

$$
\Delta U_{1}=\int_{0}^{\infty} \int_{0}^{\infty}\left\{u_{1}\left(S_{1}-y-\varepsilon\right)-u_{1}\left(S_{1}-y\right)\right\} d F_{1}\left(x_{1}\right) d F_{2}\left(x_{2}\right)
$$

Since $\varepsilon\left(x_{1}, x_{2}\right)$ is small in absolute value, we can write

$$
u_{1}\left(S_{1}-y-\varepsilon\right)-u_{1}\left(S_{1}-y\right)=-u_{1}^{\prime}\left(S_{1}-y\right) \varepsilon\left(x_{1}, x_{2}\right)
$$

hence

$$
\Delta U_{1}=-\int_{0}^{\infty} \int_{0}^{\infty} u_{1}^{\prime}\left(S_{1}-y\right) \varepsilon\left(x_{1}, x_{2}\right) d F_{1}\left(x_{1}\right) d F_{2}\left(x_{2}\right.
$$

For Company II we find

$$
\Delta U_{2}=\int_{0}^{\infty} \int_{0}^{\infty} u_{2}^{\prime}\left(S_{2}-x_{1}-x_{2}+y\right) \varepsilon\left(x_{1}, x_{2}\right) d F_{1}\left(x_{1}\right) d F_{2}\left(x_{2}\right)
$$

Both $\Delta U_{1}$ and $\Delta U_{2}$ will change sign with $\varepsilon\left(x_{1}, x_{2}\right)$. Hence to make certain that the inequalities

$$
\Delta U_{1}>0 \text { and } \Delta U_{2}>0
$$

are not both satiesfied for any $\varepsilon\left(x_{1}, x_{0}\right)$ we must require that

$$
\Delta U_{1} \Delta U_{2} \leq \text { o for all } \varepsilon\left(x_{1}, x_{2}\right) \text {. }
$$

A sufficient condition is that

$$
u_{\mathrm{a}}^{\prime}\left(S_{2}-x_{1}-x_{2}+y\right)=k u_{1}^{\prime}\left(S_{1}-y\right)
$$

where $k$ is a positive constant.

If this condition is satisfied we have

$$
\Delta U_{1} \Delta U_{2}=-k\left\{\int_{0}^{\infty} \int_{0}^{\infty} u_{1}^{\prime}\left(S_{1}-y\right) \varepsilon\left(x_{1}, x_{2}\right) d F_{1}\left(x_{1}\right) d F_{2}\left(x_{2}\right)\right\}^{2}
$$

3.4. To prove that the condition also is necessary, we put

$$
u_{2}^{\prime}\left(S_{2}-x_{1}-x_{2}+y\right)=k\left\{u_{1}\left(S_{1}-y\right)+v\left(x_{1}, x_{2}\right)\right\}
$$

where $v\left(x_{1}, x_{2}\right)=0$ except over a set $A$. 
We can then show that unless

$$
\int_{A} d F_{1}\left(x_{1}\right) d F_{2}\left(x_{2}\right)=0
$$

it will be possible to find a function $\varepsilon\left(x_{1}, x_{2}\right)$ such that

$\Delta U_{1} \Delta U_{2}>0$. This proves the statement.

3.5. We have thus found that the Pareto optimal set consists of the functions $y\left(x_{1}, x_{2}\right)$ which satisfy the condition

$$
u_{2}^{\prime}\left(S_{2}-x_{1}-x_{2}+y\right)=k u_{1}^{\prime}\left(S_{1}-y\right)
$$

We have previously assumed that $u_{1}(x)$ and $u_{2}(x)$ are nondecreasing functions. If further we assume that $u_{1}^{\prime}(x)$ and $u_{2}^{\prime}(x)$ are monotonic decreasing functions (decreasing marginal utility of money), there will correspond at most one function $y\left(x_{1}, x_{2}\right)$ to any value of $k$. Hence the purpose of the negotiations between the companies is to agree on one value of $k$. It is easy to see that $y$ will increase with $k$. Hence the smaller $k$ is, the more favourable will the treaty be to Company I. Company II on the other hand will try to obtain agreement on the largest possible value of $k$.

We note that $y$ does not depend on $x_{1}$ and $x_{2}$ separately, but only on their sum $x_{1}+x_{2}=z$, so that the treaty can be defined by a function $y(z, k)$.

The Nash solution to our problem will then be the value of $k$ which maximises

$$
\left\{U_{1}(y(z, k))-U_{1}(0)\right\} \quad\left\{U_{2}(y(z, k))-U_{2}(0)\right\}
$$

3.6. It is remarkable that $y(z, k)$ depends only on the utility functions $u_{1}(x)$ and $u_{2}(x)$ and not on the risk distributions $F_{1}(x)$ and $F_{2}(x)$. This means that the type of reinsurance treaty which is optimal to two companies, depends only on the objectives which the companies pursue, or if one prefers another formulation, on the attitude to risk which determines these objectives. The composition of the portfolios, as expressed by the risk distributions, enters into the play only when it comes to selecting a particular value of $k$.

3.7. The preceeding paragraphs should make it clear that a prerequisite to a rational theory of reinsurance is an operational statement of the objectives which the companies pursue. By "operational" is meant that the objectives are reduced to that of maximising a mathematical expression. 
Very little is known about these objectives. The few "statements of policy" which one finds from time to time are usually too incomplete to make an operational formulation possible. In some cases one may suspect that a statement of objectives, if completed, would prove inconsistent. It does therefore not seem to be a very promising approach to collect statements of policy and try to derive from them the properties of the functions which insurance companies try to maximise in their dealings on the reinsurance market.

Another approach would be from the normative point of view. From some general considerations one could probably lay down a set of rules as to what objectives an insurance company ought to pursue in its reinsurance policy. From these rules one could then deprive the characteristics of the function which the company should seek to maximise.

However, before taking up any of these lines of thought, it is useful to gain some knowledge about the nature of the relations between the utility function and the optimal treaty. We will therefore in the following section study a few particular cases. We will select some mathematically simple and economically acceptable functions to represent the utility of money and find the form of treaty which in each case is optimal.

\section{Some Special Cases}

4.1. The simplest possible case appears to be that of both companies having a linear utility of money, so we are led to consider:

Example I

$$
u_{1}(x)=a_{1} x+b_{1} \text { and } u_{2}(x)=a_{2} x+b_{2}
$$

It is easy to see that in this case the sole objective of the companies is to maximise expected profits. This means that the companies will not take into consideration the possibility of losses which may occur owing to deviations from the expected value of the amount of claims. It is intuitively clear that in this case there is no reason for an exchange of risks between the two companies. This is also brought out by the condition found in para 3.5 


$$
u_{2}^{\prime}\left(S_{2}-z+y\right)=k u_{1}^{\prime}\left(S_{1}-y\right)
$$

which in this case is reduced to

$$
a_{\mathbf{2}}=a_{1} k
$$

Since the utility function is determined only up to a linear transformation, the coefficients $a_{1}$ and $a_{2}$ have no significance, so that the condition can determine neither a value $k$, nor a function $y\left(x_{1}, x_{2}\right)$.

4.2. As the first non-trivial case we will consider: Example 2

$$
\begin{aligned}
& u_{1}(x)=-x^{2}+a x \\
& u_{2}(x)=x
\end{aligned}
$$

The utility function $u_{1}(x)=-x^{2}+a x$ has been studied in some detail in a previous paper (5). It has an acceptable shape for $x<\frac{1}{2} a$. For $x>\frac{1}{2} a$ utility will decrease with increasing $x$, and this seems unreasonable. If no claims occur, the company's funds $S_{1}$ will become a clear profit. The utility function ought to be such that this result appears as the best possible outcome of the company's underwriting, i.e. we should have $2 S_{1}<a$.

To rule out any distortions due to decreasing utility of money; we will assume that $2\left(S_{1}+S_{2}\right)<a$.

It is clear that the greater $a$ is, the greater is the weight the company attaches to expected profits as compared to the weight given to possible losses.

The function $y(z, k)$ is determined by the relation

$$
u_{2}^{\prime}\left(S_{2}-z+y\right)=k u_{1}^{\prime}\left(S_{1}-y\right)
$$

In this example it is convenient to write $\frac{\mathrm{I}}{k}$ in stead of $k$, so that the relation becomes:

$$
k=-2\left(S_{1}-y\right)+a
$$

which gives

$$
y(z, k)=S_{1}-\frac{1}{2}(a-k)
$$

We see that $y(z, k)$, i.e. the amount which Company I shall pay, does not depend on $x_{1}$ and $x_{2}$. Hence the optimal treaty is that Company II shall take over liability for the whole portfolio of Company I, against a compensation of $S_{1}-\frac{1}{2}(a-k)$. 
It is not difficult to see that this must be the outcome of the negotiations between the two companies. In this example Company II is not worried about risk of loss. It will accept any insurance contract as long as the premium it receives is just greater than the expected amount of claims. However, in its negotiations with Company I, Company II obviously tries to obtain a compensation greater than this minimum premium. Company I on the other hand has a certain risk aversion. This means that it is willing to part with its whole portfolio, if it can retain a sufficiently large part of its funds. It will therefore try to pass on its total liability to Company II, against the lowest possible payment.

4.3. Since this example is very simple, it is useful to analyse it in some further detail. This will illustrate a number of points which it will be difficult to bring out clearly in the more complicated examples which will be considered later.

For the initial utilities we have:

Company I

$$
U_{1}(0)=\int_{0}^{\infty}\left\{-\left(S_{1}-x\right)_{0}+a\left(S_{1}-x\right)\right\} d F(x)
$$

or

$$
U_{1}(\mathrm{o})=-\left(S_{1}-P_{1}\right)^{2}+a\left(S_{1}-P_{1}\right)-V_{1}
$$

where $P_{1}=\int_{0}^{\infty} x d F_{1}(x)$ - the mean of the risk distribution - can be interpreted as the net premium of the company's portfolio, and where

$$
V_{1}=\int_{0}^{\infty}\left(x-P_{1}\right)^{2} d F_{1}(x)
$$

is the variance of the risk distribution.

Company II

$$
U_{2}(\mathrm{o})=\int_{0}^{\infty}\left(S_{2}-x\right)^{2} d F_{2}(x)=S_{2}-P_{2}
$$

After the conclusion of the treaty, the utilities will be: Company I

$$
U_{1}(y)=-\left(\frac{1}{2}(a-k)\right)^{2}+a\left(\frac{1}{2}(a-k)\right)
$$

or

$$
U_{1}(y)=\frac{1}{4}\left(a^{2}-k^{2}\right)
$$




\section{Company II}

$$
U_{2}(y)=S_{1}+S_{2}-\left(P_{1}+P_{2}\right)-\frac{1}{2}(a-k)
$$

It is easily verified that

and

$$
U_{1}(y)>U_{1}(0) \text { for } k<\sqrt{\left(a-2\left(S_{1}-P_{1}\right)\right)^{2}+4 V_{1}}
$$

$$
U_{2}(y)>U_{2}(0) \text { for } k>a-2\left(S_{1}-P_{1}\right)
$$

Hence both companies will increase their utility if they agree on a value of $k$ which satisfies the condition

$$
a-2\left(S_{1}-P_{1}\right)<k<\sqrt{\left(a-2\left(S_{1}-P_{1}\right)\right)^{2}+4 V_{1}}
$$

4.4. From our general assumptions of rationality and cooperation we can only deduce that the companies will agree on some value of $k$ in this interval. In order to determine which value they will agree upon, we must, as mentioned in para 3.2 introduce some additional assumptions.

According to the assumptions made by Nash, the companies will agree on the value of $k$ which maximises the product:

$$
\left\{U_{1}(y)-U_{1}(0)\right\} \quad\left\{U_{2}(y)-U_{2}(0)\right\}
$$

which in this particular case becomes:

$$
\begin{aligned}
& \left\{S_{1}-P_{1}-\frac{1}{2}(a-k)\right\}\left\{\frac{1}{4}\left(a^{2}-k^{2}\right)+\left(S_{1}-P_{1}\right)^{2}-\right. \\
& \left.-a\left(S_{1}-P_{1}\right)+V_{1}\right\}
\end{aligned}
$$

This value is found to be:

$$
k=\frac{2}{3} \sqrt{\left(a-2\left(S_{1}-P_{1}\right)\right)^{2}+4 V_{1}}+\frac{\mathrm{I}}{3}\left(a-2\left(S_{1}-P_{1}\right)\right)
$$

which is the Nash solution to the problem.

We note that as $V_{1}$ increases, $k$ will increase, and hence the treaty will become more and more favourable to Company II. This illustrates one of the essential points in a bargaining situation. The greater $V_{1}$ is, the more anxious will Company I be to obtain some reinsurance cover. Company II, knowing this, will take advantage of the situation and exact a higher price.

It is also easy to show that the amount which Company I pays, i.e. $S_{1}-\frac{1}{2}(a-k)$ will decrease with increasing $a$, if $k$ is determined as the Nash solution. This means that the less Company I is con- 
cerned over the possibilities of loss, the better is the bargain it can make with Company II.

\subsection{Example 3}

$$
\begin{aligned}
& u_{1}(x)=-x^{2}+a_{1} x \\
& u_{2}(x)=-x^{2}+a_{2} x
\end{aligned}
$$

The function $y(z, k)$ is determined by

$$
-2\left(S_{2}-z+y\right)+a_{2}=k\left(-2\left(S_{1}-y\right)+a_{1}\right)
$$

which gives

$$
y(z, k)=\frac{\mathrm{I}}{\mathrm{I}+k} z+\frac{k}{\mathrm{I}+k} S_{1}-\frac{\mathrm{I}}{\mathrm{I}+k} S_{\mathbf{2}}+\frac{a_{2}-a_{1} k}{2(\mathrm{I}+k)}
$$

By some rearrangement this can be written:

$$
\begin{array}{r}
y\left(x_{1}, x_{2}\right)=\frac{\mathrm{I}}{\mathrm{I}+k}\left(x_{1}+x_{2}\right)+\frac{k}{\mathrm{I}+k} P_{1}-\frac{\mathrm{I}}{\mathrm{I}+k} P_{2}+ \\
+\frac{2\left(S_{1}-P_{1}\right)-2 k\left(S_{2}-P_{2}\right)+a_{2}-a_{1} k}{2(\mathrm{I}+k)}
\end{array}
$$

It is easy to see that in this case the optimal treaty is an exchange of quota shares.

Company I cedes a quota $\frac{k}{I+k}$ of its premium to Company II. If a claim $x_{1}$ occurs in the portfolio of Company I, this company will pay only the retained quota $\mathrm{I}-\frac{k}{\mathrm{I}+k}=\frac{\mathrm{I}}{\mathrm{I}+k}$

Similarly Company II cedes a quota $\frac{I}{I+k}$ of its premium $P_{2}$, and Company I pays the amount $\frac{\mathrm{I}}{\mathrm{I}+k} x_{2}$ if a claim amounting to $x_{2}$ occurs in the portfolio of Company II.

It is worth noting that the quotas ceded add up to unity.

4.6. Example 4

$$
\begin{aligned}
& u_{1}(x)=x^{5} \\
& u_{2}(x)=-x^{2}+a x
\end{aligned}
$$

The function $u_{1}(x)=x^{t}$ appears fairly acceptable as the utility function of an insurance company. For large positive values of 
$x$ the function increases very slowly, and this seems quite plausible for a company which is not primarily concerned with making large profits. The rapid fall in utility as $x$ decreases towards and through zero also seems acceptable. The function's behaviour for large negative values of $x$ is not so satisfactory, although it may be possible to provide some justification.

The function $y(z, k)$ is determined by:

$$
-2\left(S_{2}-z+y\right)+a=\frac{k}{3}\left(S_{1}-y\right)^{-\frac{2}{3}}
$$

This is an equation of the 5 th degree in $y$. To discuss its roots, we solve with respect to $z$ and find:

$$
z=y-\frac{1}{2} a+S_{2}+\frac{k}{6}\left(S_{1}-y\right)^{-\frac{2}{3}}
$$

From this expression we see that:

(i) As $y$ increases from $-\infty$ to $S_{1}, z$ will increase from $-\infty$ to $+\infty$.

(ii) As $y$ increases from $S_{1}$ to $+\infty, z$ will decrease from $+\infty$ to a certain minimum, and then increase to $+\infty$.

Hence to a given value of $z$ there may correspond three values of $y$. However, two of these values will be greater than $S_{1}$, and this obviously has no meaning. $y(z, k)>S_{1}$ for all $z$ and $k$ means that Company I accepts ruin in advance by agreeing to pay out more than the total of its funds, regardless of what the claims may amount to. However, there exists, for any positive $z$ a unique function $y(z, k) \leq S_{1}$ which represents the Pareto optimal treaties.

It is clear that this set of treaties will give Company I an assurance against ruin, since regardless of what the claims are, Company I will never be called upon to pay more than $S_{1}$. The optimal treaty is thus very similar to a familiar Stop Loss cover.

\subsection{Example 5}

$$
\begin{aligned}
& u_{1}(x)=\log x \\
& u_{2}(x)=-x^{2}+a x
\end{aligned}
$$

$\log x$ is the utility function first proposed by Daniel Bernoulli. The function is not particularly suitable for our purpose, so we will study it owing to its historical interest, and also because 
it may be useful as a limiting case of more acceptable functions. The function $y(z, k)$ is given by

$$
-2\left(S_{2}-z+y\right)+a=\frac{k}{S_{1}-y}
$$

from which we obtain

$$
y=\frac{\mathrm{I}}{4}\left(a+2 S_{1}-2 S_{2}+2 z \pm \sqrt{\left(a-2 S_{1}-2 S_{2}+2 z\right)^{2}+8 k}\right.
$$

If we take the square root with positive sign, we get

$$
y(z, k)>\frac{1}{2} a-S_{2} \text { for all } k
$$

This means that we for all $z$ and $k$ will have $S_{1}<y(z, k)$, since we have assumed in para 4.2 that $2\left(S_{1}+S_{2}\right)<a$. Hence we discard this case as meaningless, as we did it in the preceeding example. Taking the negative sign of the square root, we get as the unique solution a function

$$
y(z, k)<S_{1} \text { for all } z \text { and } k .
$$

Hence the optimal treaty is also in this case a kind of Stop Loss cover.

4.8. It is interesting to compare the two last examples. It is clear that Company $I$ is in a much stronger bargaining position in Example 4 than in Example 5. In the former example the company is able to face the disagreeable prospect of ruin with some equanimity. It should therefore be able to make a favourable deal with Company II.

In Example 5 the company considers its risk situation as infinitely bad if there is a probability of ruin different from zero, and the company is willing to pay any finite amount to get out of this situation. One is tempted to say that a company with this attitude to risk has nothing to do in the insurance business. Company II will obviously take advantage of this situation and drive a hard bargain. Since the initial utility of Company $I$ is $-\infty$, the case is messy and difficult to analyse in a neat manner, for instance we can not apply Nash's methods without modifications. However, it is easy to see that almost any reasonable assumptions will lead to a treaty whereby Company II takes over the whole portfolio and all the funds of Company $\mathrm{I}$. 
4.9. It is also interesting to compare Example 2 and Example 5, since in both cases the optimal solution was that Company I should hand its whole portfolio over to Company II. However, in Example 2 Company I did not feel compelled to get rid of its portfolio. On the contrary it may be more to the point to say that Company I takes advantage of the lighthearted attitude to risk of Company II, and gets rid of its liability on favourable terms. Company I may for instance be able to keep as profits a part of the safety loading in the premium it charged on its direct underwriting.

4.10. All the examples discussed above have given optimal treaties which in important aspects differ from the reinsurance arrangements we know from practice. However, these treaties are optimal only in our two-company model, and only under the assumptions which we have made. Before even thinking of applying our results in practice, we must examine the model critically. This is done in the following section.

\section{Limitations of the Model}

5.1. The most obvious limitation is that our model only deals with the negotiations between two companies. This point has already been discussed in para I.3. It is well known from the theory of games that the situation will change radically if a third company enters into the negotiations. This is brought out clearly in Example 5. Here Company I considers itself in desperate need of reinsurance, and Company II takes advantage of this to acquire all the funds of Company I. If, however, a Company III should make a competing offer, which would enable Company I to retain a part of its funds, this offer will obviously be preferred to the harsh terms dictated by Company II. This may again induce Company II to make a better offer. If there is no "collusion" between Companies II and III, the problem will have a solution. In general the solution will be a treaty such that any treaty more favourable to Company I would give at least one of the Companies II and III a lower utility than they have in the initial solution.

However, if Companies II and III should agree to join in exercising pressure on Company I, this company would have to part with 
all its funds. The two other companies would then have to bargain on how they should divide between themselves the proceeds of their collusion.

Neither the theory of games, nor other theories of oligopoly are at the present time able to deal with the problem of collusion in a fully satisfactory manner. It therefore seems extremely difficult to extend the model to include more than two companies, except in the case of perfect competition, or no collusion. This problem will be the subject of a forthcoming paper (6).

5.2. As mentioned in para 2.4 our model does not take into consideration the possibility that the reinsurer may be ruined. In Examples 4 and 5 in Section 4 we found optimal treaties which implied that Company I should pay more than its total funds to Company II. These treaties appeared as optimal because they would be extremely favourable to Company II if they could be carried out. In the two examples mentioned we were able to reject these treaties. However, the same factor has obviously had some influence also in the other examples and may have distorted the results.

We do not propose to study this difficulty any further, since it is almost entirely of our own making. It has been brought into the model by our drastic simplifications, and is likely to disappear in a more general and a more realistic model.

5.3. The model we have studied appears to be completely static. The risk distribution $F(x)$ was presented as the probability that the portfolio in hand on a certain day should lead to an amount of claims not exceeding $x$ by the time when all contracts in the portfolio have expired. If one can assume that new business comes in at a rate which will keep the company's risk distribution fairly constant over a certain period of time, the model may have some practical applicability, although certainly of a very limited scope.

However, there should be no principal difficulty involved in replacing the risk distribution $F(x)$ by a stochastic process $F(x, t)$ and develop a more general theory. This would leave a major part of our formulae virtually unchanged, whilst the text would have to be reworded, and considerably more care would be required in the mathematical proofs. We have not attempted such a generalisation in the present paper, since this inevitably would have 
focussed attention on purely mathematical problems, which really are of secondary importance. The essential elements are the companies' evaluation of risk situations, and the ways in which companies can improve their risk situation through reinsurance arrangements, and these elements can best be understood by a detailed analysis of a simple and manageable model.

5.4. Our model assumes that both risk distributions are given, or rather that both companies consider them as given. Behind this there must be some assumption that the two companies agree on the evaluation of every probability which enters into either portfolio. It was this assumption which in para 3.5 led to optimal treaties implying that the companies should pool their portfolios, and then seek an agreement as to how the total amount of claims occuring in the joint portfolio should be divided between the companies.

If now one company proposes to put into the pool a contract according to which a claim $x$ may occur with a probability $p$, the other company may suspect that the probability is underestimated. This company can either refuse to let the contract enter the pool, or it can demand that the first company as a proof of good faith shall retain a part of this contract on its own account, and only let the remainder go into the pool. We shall not elaborate this point. It is evident that considerations such as those above will lead to treaties of a more familiar kind, based on reinsurance of excedents.

5.5. The assumptions, referred to in para 2.6 , which make it possible to represent a scale of values for risk situations by a real valued utility function, are usually referred to as the Bernowillian hypothesis. The hypothesis has been severely criticised by some authors such as Allais (I). However, most authors seem to accept it as a normative rule for decision making under uncertainty. It has been shown by Chipman (7) that under weaker assumptions utility can be represented by a vector in a "lexicographical" ordering. We will not here explore the possibilities offered by Chipman's approach, although his utility concept seems very suitable for analysing some statements of objectives made by insurance companies. 
5.6. In our model the only purpose of reinsurance is to improve the risk situation of the company. In practice there are number of other factors which must be taken into account. For instance to a small company the contact with a large reinsurance company may be very valuable in itself. The reinsurer will be able to provide the company with useful advice and information from his worldwide connections and experience. On the other hand, a reciprocal treaty may have some inherent disadvantages to two companies which compete against each other, since the treaty necessitates making available a considerable amount of information to the competitor.

These factors are closely related to what authors on the theory of games refer to as "the pleasure derived from the game", and "the cost of playing the game". They are usually dismissed as being only of secondary importance, and do not seem to have been studied very much. We will not at the present study these factors, although they may justify some reinsurance treaties which appear irrational according to a simplified theory.

\section{Conclusion}

6.1. The concept of utility has played a rather obscure part in economics and statistics since it was first introduced by Daniel Bernoulli (3) more than 220 years ago. The concept enjoyed a comparatively brief period of respectability when the Austrian School made marginal utility the very corner stone of economic theory. The recent popularity of utility is due to von Neumann and Morgenstern (Io) who made measurable utility an essential part of their "Theorie of Games". Owing to the vast range of problems to which this theory can be applied, utility has become an apparently indispensable element in rational decision making, scientific management and other disciplines closely related to the problems of reinsurance.

6.2. Nolfi seems to have been the first to apply the modern utility concept to problems in insurance mathematics. In his first application (II) he studies the utility function of an insured person. In a later paper (I2) he studies the utility function which 
an insurance company should maximise when deciding what safety loading to include in its premiums. This function weighs the loss which may occur if the loading is too small, against the possible inconveniences of a too heavy loading. This latter problem has also been discussed by Bierlein (4).

6.3. The utility functions used by these authors seem plausible, and lead to reasonable results. One could, however, think of other functions which seem equally acceptable, but which will lead to very different, although still reasonable results.

The same applies to the utility functions studied in the present paper. Few of the functions discussed in the examples are so obviously unreasonable that they can be rejected outright. However, the various functions lead to very different optimal treaties. We have no means of saying which of these solutions are right or wrong, in general, or for particular types of insurance companies.

6.4. The inescapable conclusion seems to be that we know far too little about the objectives which insurance companies pursue, or ought to pursue in their reinsurance policy. However, unless these objectives can be spelt out in an operational manner, it is difficult to deny that the whole theory of risk and reinsurance hangs in the air. It is also difficult to see how one can avoid some concept of utility in order to build a firm foundation under this theory.

\section{REFERENCES}

(I) Aliais, M.: "Le Comportement de l'Homme Rationnel devant le Risque: Critique des Postulats et Axiomes de l'Ecole Americaine", Econometrica, Vol. 23, pp. 503-546.

(2) Benktander, G.: Contribution to the discussion. Transactions of the $X V I$ International Congress of Actuaries, Vol. 3, pp.

(3) Bernoulin, D.: "Specimen Theoriae Novae de Mensura Sortis", St. Petersburg 1738. English translation Econometrica, Vol. 22, pp. 23-36.

(4) BIERLEIN, D.: "Spieltheoretische Modelle für Entscheidungssituationen des Versicherers", Blätter der Deutschen Gesellschaft für VersicherungsMathematik. Vol. III, pp. 46I-469.

(5) BoRcH, K.: "Reciprocal Reinsurance Treaties seen as a Two-Person Co-operative Game", Skandinavisk Aktuarietidskrift, I96o, pp.

(6) Borch, K.: "Equilibrium in a Reinsurance Market" To be published.

(7) Chipman, J. S.: "The Foundations of Utility", Econometrica, Vol, 28, pp. 193-224.

(8) Golding, C. E.: "The Law and Practice of Reinsurance", Buckley Press, London 1954. 
(9) Nash, J. F.: "The Bargaining Problem", Econometrica, Vol. I8, pp. I55-I62.

(ro) Neumann, J. von and O. Morgenstern: "Theory of Games and Economic Behavior, Princeton 1944.

(i I) Nolfi, P.: "Zur mathematischen Darstellung des Nutzens in der Versicherung". Mitteilungen der Veveinigung schweizerischer Versicherungsmathematiker. Vol. 55, pp. 395-407.

(12) NOLFI, P.: "Die Beriicksichtigung der. Sterblichkeitsverbesserung in der Rentenversicherung nach der Optimalmethode der Spieltheorie", Mitteilungen der l'ereinigung schweizerischer Versicherungsmathematiker, Vol. 59, pp. 29-48. 